Canadian

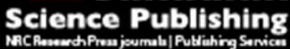

Applied Physiology, Nutrition, and Metabolism Physiologie appliquée, nutrition et métabolisme

\title{
Gut-training: The impact of two weeks repetitive gut- challenge during exercise on gastrointestinal status, glucose availability, fuel kinetics, and running performance.
}

\begin{tabular}{|r|l|}
\hline Journal: & Applied Physiology, Nutrition, and Metabolism \\
\hline Manuscript ID & apnm-2016-0453.R4 \\
\hline Manuscript Type: & Article \\
\hline Date Submitted by the Author: & 01-Jan-2017 \\
\hline Complete List of Authors: & $\begin{array}{l}\text { Costa, Ricardo; Monash University, Nutrition and Dietetics } \\
\text { Miall, Atlanta; Monash University, Nutrition and Dietetics } \\
\text { Khoo, Anthony; Monash University, Nutrition and Dietetics } \\
\text { Rauch, Christopher; Monash University, Nutrition and Dietetics } \\
\text { Snipe, Rhiannon; Monash University, Nutrition and Dietetics } \\
\text { Camões-Costa, Vera; Monash University, Nutrition and Dietetics } \\
\text { Gibson, Peter; Monash University, Gastroenterology }\end{array}$ \\
\hline Keyword: & $\begin{array}{l}\text { exercise, carbohydrate, I-FABP, breath hydrogen, gastrointestinal } \\
\text { symptoms }\end{array}$ \\
\hline \multicolumn{2}{|c}{} \\
\hline
\end{tabular}


Gut-training: The impact of two weeks repetitive gut-challenge during exercise on gastrointestinal status, glucose availability, fuel kinetics, and running performance.

Ricardo J.S. Costa ${ }^{1}$, Atlanta Miall ${ }^{1}$, Anthony Khoo ${ }^{1}$, Christopher Rauch ${ }^{1}$, Rhiannon Snipe ${ }^{1}$, Vera Camões-Costa ${ }^{1}$, Peter Gibson ${ }^{2}$.

${ }^{1}$ Monash University, Department of Nutrition \& Dietetics, Level 1, 264 Ferntree Gully road, Notting Hill, 3168 Victoria, Australia.

${ }^{2}$ Monash University, Department of Gastroenterology- The Alfred Hospital, 55 Commercial road, Melbourne, 3004 Victoria, Australia

\section{Corresponding author:}

Ricardo J.S. Costa: Monash University, Department of Nutrition \& Dietetics, Level 1, 264 Ferntree Gully Road, Notting Hill, 3168, Victoria, Australia. Telephone: 00613 99024270. Email: ricardo.costa@monash.edu

Atlanta Miall (atlantamiall@gmail.com), Anthony Khoo (aykho3@student.monash.edu), Christopher Rauch (chrisrauch1@hotmail.com), Rhiannon Snipe (rhiannon.snipe@monash.edu), Vera Camões-Costa (vera.costa@monash.edu), Peter Gibson (peter.gibson@monash.edu). 


\section{Abstract}

Background: Due to gastrointestinal tract adaptability, the study aimed to determine the impact of two weeks gut-training protocol over two weeks on gastrointestinal status, blood glucose availability, fuel kinetics, and running performance. Methods: Endurance runners $(n=25)$ performed a gut-challenge trial (GC1), comprising of $2 \mathrm{~h}$ running exercise at $60 \% \mathrm{VO}_{2 \max }$ whilst consuming gel-discs containing $30 \mathrm{~g}$ carbohydrates $(2: 1$ glucose-fructose, $10 \% \mathrm{w} / \mathrm{v})$ every $20 \mathrm{~min}$, and a $1 \mathrm{~h}$ distance test. Participants were then randomly assigned to a carbohydrate gel-disc (CHOS), carbohydrate food (CHO-F), or placebo (PLA) gut-training group for a two weeks repetitive gutchallenge intervention. Participants then repeated a second gut-challenge trial (GC2). Results: Gastrointestinal symptoms reduced in GC2 on CHO-S $(60 \% ; p=0.008)$ and $\mathrm{CHO}-\mathrm{F}(63 \% ; p=$ 0.046); reductions were greater than PLA $(p<0.05) . \mathrm{H}_{2}$ peak was lower in GC2 on CHO-S (mean (CI): 6 (4-8) ppm) compared with CHO-F (9 (6-12) ppm) and PLA (12 (2-21) ppm) (trial*time: $p<$ 0.001). Blood glucose concentration was higher in GC2 on CHO-S (7.2 (6.3-8.1) $\left.\mathrm{mMol} \cdot \mathrm{L}^{-1}\right)$ compared with CHO-F (6.1 (5.7-6.5) $\left.\mathrm{mMol} \cdot \mathrm{L}^{-1}\right)$ and PLA $\left(6.2(4.9-7.5) \mathrm{mMol} \cdot \mathrm{L}^{-1}\right)$ (trial*time: $p=$ 0.015). No difference in oxidation rates, plasma I-FABP and cortisol concentrations were observed between groups and trials. Distance test improved on CHO-S (5.2\%) and CHO-F (4.3\%) in GC2, but not on PLA (-2.1\%) (trial*time: $p=0.009)$. Conclusion: Two weeks of gut-training with CHO-S and CHO-F improved gastrointestinal symptoms and running performance compared with PLA. CHO-S also reduced malabsorption and increased blood glucose availability during endurance running compared with PLA.

Keywords: Exercise, carbohydrates, I-FABP, breath hydrogen, gastrointestinal symptoms. 


\section{Introduction}

It is well established that the provisions of carbohydrate during exercise (i.e., $\geq 2 \mathrm{~h}$ ) is a prime determinant of endurance exercise performance (Stellingwerff and Cox 2014). Recently, the role of implementing multiple-transportable carbohydrates (e.g., 2:1 glucose to fructose ratio), up to $90 \mathrm{~g} \cdot \mathrm{h}^{-1}$, during exercise bouts lasting $\geq 3 \mathrm{~h}$, has been advocated and shown to enhance exogenous carbohydrate oxidation rates, postpone fatigue, and improve endurance performance compared with singular carbohydrate sources (e.g., glucose) (Burke et al. 2011; Jeukendrup 2010). However, the majority of original investigations used to establish recommendations for multiple-transportable carbohydrate intake during exercise have been predominantly performed on small numbers of highly-trained male cyclists (Jentjens et al. 2004; Jentjens et al. 2006; Jentjens and Jeukendrup 2005), which constitutes a minor proportion of the overall endurance sports population. Whereas, research into carbohydrate provisions during prolonged exercise in recreational endurance athletes, female athletes, and the general running populations is scarce.

There has recently been concerns raised by sports nutrition practitioners and endurance athletes that such high doses of multiple-transportable carbohydrates consumed during exercise are not tolerable, leading to debilitating gastrointestinal symptoms. Despite carbohydrate intake rates of $78 \mathrm{~g} \cdot \mathrm{h}^{-1}(1: 1: 1$ glucose-fructose-maltodextrin) during $2 \mathrm{~h}$ of steady state exercise being reported to be generally well tolerated in response to a $20 \mathrm{~km}$ cycling time trial and in a cycling focused population (Smith et al. 2013), field-based studies report average ad libitum carbohydrate intakes during a marathon of $35 \mathrm{~g} \cdot \mathrm{h}^{-1}$, and ultra-marathon events ranging from 24 to $37 \mathrm{~g} \cdot \mathrm{h}^{-1}$, irrespective of ultra-marathon runners carrying multiple-transportable carbohydrate rich foods and fluids equating to $>60 \mathrm{gCHO} \cdot \mathrm{h}^{-1}$ in the latter (Costa et al. 2013; Costa et al. 2014; Pfeiffer et al. 2012).

Fructose malabsorption has been reported with ingestion above tolerance levels (Ebert and Witt 2016, Fedewa and Rao 2014). However, the adjunct ingestion of glucose with fructose appears to lower the malabsorption rate in response to a fructose challenge in a resting state (Truswell et al. 1988). There are reports that the ingestion of multiple-transportable carbohydrates reduces the so- 
called 'gut distress' during exercise; however the majority of research has focused on markers of exogenous carbohydrate oxidation and performance in cycling, with minimal efforts being made to comprehensively assess gastrointestinal perturbations and (or) symptoms, especially in running (Rowland et al. 2015). Considering running exercise (i.e., $1 \mathrm{~h}$ at $70 \% \mathrm{VO}_{2 \max }$ ) compromises intestinal carbohydrate transporters (Lang et al. 2006), it is plausible that the inclusion of slowly absorbed and high fermentable fructose in sport nutrition formulation might be contributing to the symptom burden, irrespective of glucose presence. Fructose ingestion is associated with increased small intestinal water content (Murray et al. 2014), and this is believed to be associated with gastrointestinal symptom induction and heightened severity during episodes of malabsorption, which is prevalent within the general population (Putkonen et al. 2013; Gibson et al. 2007). Moreover, it has recently been suggested that malabsorbed nutrients reaching the ileum may suppress gastric emptying and duodenal-jejunum motility via the 'ileal brake' mechanism (Shin et al. 2013), potentially exacerbating gastrointestinal symptoms during exercise.

Gastrointestinal symptoms are a common feature of endurance exercise, and appear to be more pronounced in running or endurance events that contain a running element (e.g., triathlon) compared to other exercise modes (e.g., cycling) (Pfeiffer et al. 2012; ter Steege and Kolkman 2012). For example, severe gastrointestinal symptoms have been reported in $85 \%$ and $73 \%$ of ultramarathon runners during multi-stage and $24 \mathrm{~h}$ ultra-marathons, respectively. These symptoms led to greater compromised carbohydrate intake during exercise and greater time to event completion during a multi-stage running event (i.e., consecutive days of prolonged strenuous exercise) (Costa et al. 2016); and similar symptom manifestation is reported to be a main contributing factor for endurance event withdrawal (Hoffman and Fogard 2011; Jeukendrup et al. 2000; Stuempfle and Hoffman 2015). Additionally, it has previously been observed that female runners reported higher incidence of symptoms compared with male counterparts (ter Steege et al. 2008).

The cause/s of gastrointestinal symptoms during running appear to be multifactorial in origin and stem from 'exercise-induced gastrointestinal syndrome', in which the primary driving 
factors are: 1) splanchnic hypoperfusion and subsequent intestinal epithelial injury, increased intestinal permeability, systemic responses (i.e., endotoxaemia and cytokinaemia), and impaired intestinal nutrient absorption; and 2) stress induced increases in sympathetic drive and subsequent reductions in enteric nervous system activity, which alters intestinal motility and absorption capacity (Gill et al. 2015a; Gill et al. 2015b; Grootjans et al. 2016; Leipers 2015; ter Steege and Kolkman 2012; van Wijck et al. 2012).

Due to the high adaptability of the gastrointestinal tract, it has recently been proposed that the gut can be trained to improve its ability to tolerate carbohydrate intake during exercise (Cox et al. 2010; Jeukendrup and McLaughlin 2011). With this in mind, the aim of the current study was to determine the impact of two weeks gut-training using a repetitive gut-challenge protocol during exercise on gastrointestinal status (i.e., integrity, function, and symptoms), blood glucose availability, total carbohydrate oxidation, and running performance. It was hypothesised that two weeks of gut-training would improve markers of gastrointestinal status, increase blood glucose availability and total carbohydrate oxidation, and improve running performance in response to a subsequent gut-challenge trial. 


\section{Methods}

\section{Participants}

Recreationally competitive endurance and ultra-endurance runners were invited to participate in the study. All participants gave written informed consent, which received local ethics approval and conformed to the 2008 Helsinki Declaration for Human Research Ethics. Participants were excluded if they confirmed having gastrointestinal infections, diseases and (or) disorders (e.g., coeliac disease, inflammatory bowel disease, irritable bowel syndrome, diverticular disease, gastrooesophageal reflux disease, past history of gastrointestinal surgery, and other self-reported gastrointestinal issues), consumed potential modifiers of gastrointestinal integrity (such as prebiotics, probiotics, and (or) antibiotics), were adhering to gastrointestinal-focused dietary regimes (such as low FODMAP or fibre-modified diets) within the previous three months, or consumed non-steroidal anti-inflammatory medications and (or) stool altering medications (e.g., laxatives and anti-diarrhoea) within one month before the experimental protocol.

\section{Preliminary measures}

Before the main experimental protocol, baseline height and body mass were measured. Body fat mass was determined through an 8-point multi-frequency bioelectrical impedance analyser (mBCA 515, Seca, Ecomed, Hamburg, Germany). Maximal oxygen uptake ( $\mathrm{VO}_{2 \max }$; Vmax Encore Metabolic Cart, Carefusion, San Diego, California, US) was estimated by means of a continuous incremental exercise test to volitional exhaustion on a motorized treadmill (Forma Run 500, Technogym, Seattle, Washington, US), as previously reported (Costa et al. 2009). From the $\mathrm{VO}_{2}-$ work rate relationship, the treadmill speed at $60 \% \mathrm{VO}_{2 \max }$ and $1 \%$ gradient was extrapolated and verified (mean $\left.\pm \mathrm{SD}: 10.0 \pm 1.2 \mathrm{~km} \cdot \mathrm{h}^{-1}\right)$.

\section{Experimental procedure}


A schematic description of the experimental procedure is depicted in Figure 1. Participants reported to the laboratory at 08:00 $\mathrm{h}$ after consumption of a standardised low fibre and FODMAP breakfast (2.2 MJ, $107 \mathrm{~g}$ carbohydrate, $16 \mathrm{~g}$ protein, and $3 \mathrm{~g}$ fat) with $400 \mathrm{ml}$ of water (consumed at 07:00 h) (Gill et al. 2016). Within 30 min of the initial gut-challenge trial (GC1), participants were asked to void before body mass measurements, provide a breath sample into a $250 \mathrm{ml}$ breath collection bag (Wagner Analysen Technick, Bremen, Germany), and complete a self-reported gastrointestinal symptom assessment tool. A 10 point Likert-type rating scale was used to quantify self-reported gastrointestinal symptoms, with 0 indicative of no symptom to 10 indicative of extreme symptom (5 indicative of severe symptom), as previously reported (Costa et al. 2016). Symptoms were categorised by: gut discomfort, upper-gastrointestinal symptoms (gastrooesophageal and gastro-duodenal originated: projectile vomiting, regurgitation, urge to regurgitate, gastric bloating, belching, stomach pain, and heartburn/gastric acidosis), lower-gastrointestinal symptoms (intestinal originated: flatulence including lower-abdominal bloating, urge to defecate, abdominal pain, abnormal defecation including loose water stools, diarrhoea and blood in stools), and other related symptoms (nausea, dizziness, and stitch).

[Insert Figure 1 near here]

A whole blood sample was then collected by venipuncture from an antecubital vein into one lithium heparin $\left(6 \mathrm{ml}, 1.5 \mathrm{IU} \cdot \mathrm{ml}^{-1}\right.$ heparin) vacutainer tube (Becton Dickinson, Oxford, UK). Participants then initiated (09:00 h) steady state running exercise on a motorised treadmill for $2 \mathrm{~h}$ $\left(\right.$ mean \pm SD: $23 \pm 1{ }^{\circ} \mathrm{C}, 50 \pm 8 \%$ relative humidity, and dual-fan wind speed of $10.6 \mathrm{~km} \cdot \mathrm{h}^{-1}$ ), at the previously determined treadmill speed, whilst consuming a formulated carbohydrate supplement gel-disc containing $30 \mathrm{~g}$ of carbohydrates (2:1 glucose-fructose) with accompanying water (10\% $w / v ; 316 \mathrm{mOsmol} \cdot \mathrm{kg}^{-1}$ ) at $0 \mathrm{~min}$ and every $20 \mathrm{~min}$ thereafter. Heart rate and rating of perceived exertion, as previously reported (Costa et al. 2014), and gastrointestinal symptoms were measured 
every $10 \mathrm{~min}$. Additionally, blood glucose was measured every $30 \mathrm{~min}$, breath samples were collected every $1 \mathrm{~h}$, and breath-by-breath indirect calorimetry (Vmax Encore Metabolic Cart, CaseFusion- BD, Franklin Lakes, NJ, USA) was used to determine $\mathrm{VO}_{2}, \mathrm{VCO}_{2}$, and respiratory quotient every 20 min. For consistency, all measurements and samples were recorded and collected before the carbohydrate feeding at each respective time point. Total carbohydrate and fat oxidation were calculated from the $\mathrm{VO}_{2}$ and $\mathrm{VCO}_{2}$ measured from the last 5 min of each collection point using non-protein respiratory quotient values in accordance with Péronnet and Massicotte (1991):

Total CHO oxidation: $\left(4.585 \times \mathrm{VCO}_{2}\right)-\left(3.226 \times \mathrm{VO}_{2}\right)$

Total Fat oxidation: $\left(1.695 \times \mathrm{VO}_{2}\right)-\left(1.701 \times \mathrm{VCO}_{2}\right)$

Immediately after steady state running, participants then performed a $1 \mathrm{~h}$ self-paced distance test under standardised laboratory conditions (mean $\pm \mathrm{SD}: 24 \pm 1^{\circ} \mathrm{C}, 52 \pm 8 \%$ relative humidity, and dual-fan wind speed of $10.6 \mathrm{~km} \cdot \mathrm{h}^{-1}$ ), with water provided ad libitum, as previously reported (Oliver et al. 2009). Heart rate, rating of perceived exertion and distance were recorded every 5 min. Immediately after the distance test, participants were asked to complete an additional 5 min exercise bout at the respective steady state running speed while variables were measured, as previously described. Whole blood and breath samples were collected, body mass and gastrointestinal symptoms were then measured immediately, as previously described. Additionally, breath samples were collected every $30 \mathrm{~min}$ until $4 \mathrm{~h}$, gastrointestinal symptoms were measured at $1 \mathrm{~h}$ and $2 \mathrm{~h}$, and a whole blood sample was collected at $2 \mathrm{~h}$ after the distance test.

After the completion of $\mathrm{GC1}$, participants were randomly assigned to one of three guttraining protocols: 1) a carbohydrate supplement gel-disc formulation (CHO-S) gut-training group, whereby for ten days over a period of two weeks participants performed $1 \mathrm{~h}$ running exercise equivalent to $60 \% \mathrm{VO}_{2 \max }$ whilst consuming the previously described formulated carbohydrate supplement gel-disc (carbohydrate: $30 \mathrm{~g}$, protein: trace, and fat: $0 \mathrm{~g})$ with respective water $(10 \%$ 
$w / v$ ) at $0 \mathrm{~min}, 20 \mathrm{~min}$, and $40 \mathrm{~min}$ during running on training days; 2) a placebo (PLA) gut-training group, whereby participants consumed a matched formulated gel-disc $(0.4 \mathrm{~g}$ of a $5.9 \%$ sodium saccharin solution; carbohydrate: $0 \mathrm{~g}$, protein: trace, and fat: $0 \mathrm{~g}$ ) (Sugarless liquid, Bathox Australia, Chipping Norton, NSW, Australia) with equivalent water volume at $0 \mathrm{~min}, 20 \mathrm{~min}$, and 40 min during running on training days; or 3) a carbohydrate food (CHO-F) gut-training group, whereby participants consumed a food portion equivalent to $30 \mathrm{~g}$ of carbohydrate $(1: 1$ glucosefructose ratio; carbohydrate: $30 \mathrm{~g}$, protein: $4 \mathrm{~g}$, and fat: 4g) (AmazeBalls original, Runners Kitchen, Melbourne, Victoria, Australia) with respective water $(10 \% \mathrm{w} / \mathrm{v})$ at $0 \mathrm{~min}, 20 \mathrm{~min}$, and $40 \mathrm{~min}$ during running on training days. Participants were blinded to the randomly assigned formulated geldisc groups (CHO-S and PLA) that was comprehensively matched for sight, smell, texture, flavour, taste, and after-taste. It was not possible, however, to blind participants to the CHO-F. After completion of the assigned gut-training protocol and two days of rest, participants returned to the laboratory to repeat a second gut-challenge trial (GC2), as previously described for GC1.

Participants were free to consume their normal diet throughout the experimental procedure (Costa et al. 2005, Gill et al. 2016). Dietary intake and exercise training were monitored for three days before $\mathrm{GCl}$ and throughout the gut-training protocol. Energy and nutritional intake was assessed and analysed as previously reported (Costa et al. 2013; Costa et al. 2014). Additionally, to check and confirm compliance, participants were asked to complete a gut-training adherence and completion log throughout the gut-training period.

\section{Sample analysis}

Breath samples were analysed in duplicate (coefficient of variation: 5.6\%) for hydrogen content using a gas sensitive analyser (Breathtracker Digital Microlyzer, Quintron, Milwaukee, Wisconsin, US) (Peters et al. 1994). Whole blood haemoglobin and haematocrit values were used to estimate changes in plasma volume relative to baseline and to correct plasma variables, as previously reported (Costa et al. 2014). The concentration of glucose in whole blood was 
determined from venous samples pre and post gut-challenge, and in capillary samples during running exercise through a handheld monitor (Accu-Chek Proforma, Roche Diagnostics) in duplicate (coefficient of variation: 3.0\%). The remaining whole blood samples were centrifuged at $4000 \mathrm{rpm}$ at $4^{\circ} \mathrm{C}$ for $10 \mathrm{~min}$. Plasma was aliquoted into eppendorfs and frozen at $-80^{\circ} \mathrm{C}$ prior to analysis, with the exception of $50 \mu \mathrm{l}$ lithium heparin plasma that was used to determine plasma osmolality in duplicate (coefficient of variation: $0.8 \%$ ) by freezepoint osmometry (Osmomat 030, Gonotec, Berlin, Germany). Plasma concentration of intestinal fatty acid binding protein (I-FABP) (Hycult Biotech, Uden, Netherlands), indicative of intestinal injury, and cortisol (IBL International, Hamberg, Germany), indicative of whole body stress response (Costa et al. 2005), were determined by enzyme-linked immunosorbent assay kits as per manufacturers' instructions. Each plasma variable was analysed on the same day, with standards and controls on each plate, and each participant assayed on the same plate. The intra-assay coefficient of variation for I-FABP and cortisol were $6.8 \%$ and $3.3 \%$, respectively.

\section{Statistical analysis}

Data in text and tables are presented as mean and $95 \%$ confidence interval, unless otherwise specified. Data in figures are presented as mean \pm standard deviation (SD). Two-way repeatedmeasures ANOVA (SPSS v.20, Illinois, US) was used to determine trial and time differences for variables with multiple sample points. Assumptions of homogeneity and sphericity were checked, and when appropriate adjustments to the degrees of freedom were made using the GreenhouseGeisser correction method. Significant main effects were analysed using a post hoc Tukey's HSD test. One-way ANOVA and t-tests (or non-parametric equivalents where applicable) were used to determine within-group and between-group differences for variables with a singular sample point. Spearman's rank correlation analysis was used to assess associations between variables. The acceptance level of significance was set at $p \leq 0.05$. Where applicable, relative change (i.e., \%) was used to support statistical analysis. 


\section{Results}

\section{Participants}

Of the twenty-nine participants recruited, twenty-five runners completed the experimental procedure $[n=15$ males and $n=10$ females: age 35 (32-38) y, body mass 71 (67-76) $\mathrm{kg}$, height $1.74(1.70-1.78) \mathrm{m}, \mathrm{VO}_{2 \max } 57(53-60) \mathrm{ml} \cdot \mathrm{kg}^{-1} \cdot \mathrm{min}^{-1}$, body fat mass $\left.15(13-18) \%\right]$ and were studied. Four participants failed to complete their assigned gut-training protocol (PLA $n=2$ and CHO-F $n=2)$ due to intolerance to the gut-training $(n=2)$ and participation burden $(n=2)$, and thus were excluded from the overall data set. Participants were allowed to adhere to normal training regimens during the gut-training period, which accounted for an additional 335 (206-464) min.week ${ }^{-1}$ of exercise training (i.e., swimming, cycling, running, and general strength and conditioning).

\section{Dietary intake and hydration status}

Total (and body mass adjusted) daily energy [overall cohort mean and 95\% confidence interval: $\left.11.5(10.6-12.5) \mathrm{MJ} \mathrm{day}^{-1}\left(161(149-174) \mathrm{kJ} \cdot \mathrm{kg}^{-1} \cdot \mathrm{day}^{-1}\right)\right]$, protein [121 (109-133) $\mathrm{g} \cdot \mathrm{day}^{-1}$ (1.7 (1.5-1.8) $\left.\left.\mathrm{g} \cdot \mathrm{kg}^{-1} \cdot \mathrm{day}^{-1}\right)\right]$, carbohydrate [369 (337-402) $\left.\mathrm{g} \cdot \mathrm{day}^{-1}\left(4.3(3.9-4.7) \mathrm{g} \cdot \mathrm{kg}^{-1} \cdot \mathrm{day}^{-1}\right)\right]$, fat [89 (79-99) $\left.\mathrm{g} \cdot \mathrm{day}^{-1}\left(1.2(1.1-1.4) \mathrm{g} \cdot \mathrm{kg}^{-1} \cdot \mathrm{day}^{-1}\right)\right]$, fibre [35 (31-39) $\mathrm{g} \cdot \mathrm{day}^{-1}\left(0.5(0.4-0.5) \mathrm{g} \cdot \mathrm{kg}^{-1} \cdot \mathrm{day}^{-}\right.$ $\left.\left.{ }^{1}\right)\right]$, and water $\left[2.6(2.3-2.8) \mathrm{L} \cdot \mathrm{day}^{-1}\left(36(33-40) \mathrm{ml} \cdot \mathrm{kg}^{-1} \cdot \mathrm{day}^{-1}\right)\right]$ intakes from foods and fluids during the dietary monitoring period did not differ between days in all groups, and did not differ between groups.

Exercise-induced body mass loss $(1.5(1.2-1.9) \%)$ occurred pre to post gut-challenge in all groups $(p<0.001)$, with no significant difference observed between GC1 and GC2 in all groups, and between groups. Plasma osmolality increased pre (292 (290-294) $\left.\mathrm{mOsmol} \cdot \mathrm{kg}^{-1}\right)$ to post (299 (296-302) $\left.\mathrm{mOsmol} \cdot \mathrm{kg}^{-1}\right)$ gut-challenge in all groups $(p<0.001)$, with no significant difference observed between GC1 and GC2 in all groups, and between groups. No significant difference in $a d$ 
libitum water intake $(249(188-310) \mathrm{ml})$ during the distance test was observed between GC1 and GC2 in all groups, and between groups.

Heart rate, rating of perceived exertion, and running distance test performance

Heart rate $(p<0.05)$ and rating of perceived exertion $(p<0.05)$ progressively increased throughout steady state (overall cohort mean and 95\% confidence interval: 140 (135-145) bpm and 11 (11-12), respectively) and the distance test (overall cohort mean \pm SD: 161 (155-166) bpm and 15 (14-16), respectively), and did not differ between GC1 and GC2 in all groups, and between groups. After the $1 \mathrm{~h}$ distance test, a significantly greater distance covered was observed on GC2 than GC1 on CHO-S and CHO-F, compared with PLA $(p=0.009)$ (Figure 2). Within CHO-S and CHO-F, the degree of running distance test improvement did not differ between male and female participants.

[Insert Figure 2 near here]

\section{Total carbohydrate and fat oxidation rates}

No trial*time interaction was observed for total carbohydrate and fat oxidation. However, a main effect of time was observed, whereby carbohydrate oxidation decreased $(p<0.001)$ and fat oxidation increased $(p<0.001)$ post distance test (i.e., point of stressed muscle glycogen stores) in all groups (Table 1). Male participants showed greater total carbohydrate [steady state 2.0 (1.7-2.3) $\mathrm{g} \cdot \min ^{-1}, p=0.001 ;$ and post distance test $1.3(0.9-1.7) \mathrm{g} \cdot \mathrm{min}^{-1}, p=0.003$ ] and fat [steady state 0.6 $(0.5-0.8) \mathrm{g} \cdot \mathrm{min}^{-1}, p<0.001$; and post distance test $\left.0.9(0.8-1.1) \mathrm{g} \cdot \mathrm{min}^{-1}, p<0.001\right]$ oxidation rates compared with female participants [carbohydrate: steady state $1.4(1.1-1.6) \mathrm{g} \cdot \mathrm{min}^{-1}$ and post distance test $0.8(0.6-1.0) \mathrm{g} \cdot \mathrm{min}^{-1}$; fat: steady state $0.4(0.3-0.5) \mathrm{g} \cdot \mathrm{min}^{-1}$ and post distance test 0.6 $\left.(0.5-0.7) \mathrm{g} \cdot \mathrm{min}^{-1}\right]$. When corrected for body mass, no significant difference was observed between male and female participants for total carbohydrate [males: $1.6(1.3-2.0) \mathrm{g} \mathrm{kg}^{-1} \cdot \mathrm{h}^{-1}$, females: 1.3 
$\left.(1.2-1.5) \mathrm{g} \cdot \mathrm{kg}^{-1} \cdot \mathrm{h}^{-1}\right]$ oxidation during steady state running. However, the significant differences were still apparent at post distance test for total carbohydrate [males: $1.0(0.7-1.4) \mathrm{g} \cdot \mathrm{kg}^{-1} \cdot \mathrm{h}^{-1}$, females: $0.7(0.5-0.9) \mathrm{g} \cdot \mathrm{kg}^{-1} \cdot \mathrm{h}^{-1} ; p=0.043$ ] oxidation, and total fat oxidation during both steady state running [males: $0.5(0.4-0.6) \mathrm{g} \cdot \mathrm{kg}^{-1} \cdot \mathrm{h}^{-1}$, females: $0.4(0.3-0.5) \mathrm{g} \cdot \mathrm{kg}^{-1} \cdot \mathrm{h}^{-1} ; p=0.009$ ] and post distance test [males: $0.8(0.7-0.9) \mathrm{g} \cdot \mathrm{kg}^{-1} \cdot \mathrm{h}^{-1}$, females: $\left.0.6(0.5-0.7) \mathrm{g} \cdot \mathrm{kg}^{-1} \cdot \mathrm{h}^{-1} ; p=0.001\right]$. Oxidation rates were related to body mass, with significant correlations observed between total carbohydrate $(r=0.510, p<0.001$ and $r=0.429, p=0.002)$ and fat $(r=0.594, p<0.001$ and $r=0.668, p<$ 0.001) oxidation rates with body mass during steady state running and post distance test, respectively.

[Insert Table 1 near here]

\section{Gastrointestinal symptoms}

Moderate and severe gastrointestinal symptoms were reported by $100 \%$ and $52 \%$ of participant, respectively, along GC1 (Table 2). Strong correlations were observed between gut discomfort and total gastrointestinal symptoms $(r=0.919, p<0.001)$, upper-gastrointestinal symptoms $(r=0.935, p<0.001)$, lower-gastrointestinal symptoms $(r=0.522, p<0.001)$, and nausea $(r=0.454, p=0.001)$ across the study. The total summative accumulation of rating scale point score of measurement time periods did not significantly differ for gut discomfort and symptoms between groups in GC1 and GC2 likely due to the large individual variation. However, significant improvements in gut discomfort $(p=0.018)$, total $(p=0.003)$, upper- $(p=0.043)$, lower$(p=0.010)$ gastrointestinal symptom, and nausea $(p=0.050)$ were observed on CHO-S and CHO-F compared with PLA (Table 3).

Two weeks of gut-training resulted in reduced gut discomfort during steady state running, distance test, and recovery on CHO-S (mean reduction: 44\%) and CHO-F (49\%), but did not significantly change on PLA (18\%). Reduced total gastrointestinal symptoms (60\%), upper- 
gastrointestinal symptoms (64\%), lower-gastrointestinal symptoms (40\%), and nausea (79\%) were observed in GC2 compared with GC1 on CHO-S. Reduced total gastrointestinal symptoms (63\%) upper-gastrointestinal symptoms (62\%), lower-gastrointestinal symptoms (70\%), and nausea (59\%) were observed in GC2 compared with $\mathrm{GC} 1$ on $\mathrm{CHO}-\mathrm{F}$, but lower-gastrointestinal symptoms and nausea failed to reach significance. No significant difference in gastrointestinal symptoms were observed between gut-challenge trials on PLA.

Female participants reported greater gut discomfort $(54 \%, p=0.035)$ and uppergastrointestinal symptoms $(68 \%, p=0.046)$ compared with male participants. When symptoms were corrected for body mass (i.e., normalised carbohydrate intake respective to body mass) in female and male participants, greater gut discomfort $(p=0.013)$ and upper-gastrointestinal symptoms $(p=0.027)$ were still apparent in female participants compared with male participants.

[Insert Table 2 near here]

[Insert Table 3 near here]

\section{Carbohydrate malabsorption}

In $\mathrm{GC} 1,68 \%$ of the cohort demonstrated carbohydrate malabsorption. A significant trial*time interaction was observed between groups $(p<0.001)$, whereby CHO-S presented a lower breath $\mathrm{H}_{2}$ response during recovery in GC2, compared with CHO-F and PLA (Figure 3). Compared to pre gut-challenge, in $\mathrm{GC} 1$, breath $\mathrm{H}_{2}$ significantly increased in recovery on CHO-S $(8 \pm 7 \mathrm{ppm})$, CHO-F $(9 \pm 7 \mathrm{ppm})$, and PLA (10 \pm 7 ppm). A lower peak breath $\mathrm{H}_{2}$ response $(45 \%)$ was observed on GC2 compared with GC1 on CHO-S only (Figure 3A), despite a modest reduction in breath $\mathrm{H}_{2}$ was observed during recovery on CHO-F (Figure 3B). Breath $\mathrm{H}_{2}$ responses did not differ between male and female participants. A significant correlation was observed between breath $\mathrm{H}_{2}$ responses with gut discomfort $(r=0.425, p=0.034)$ and upper-gastrointestinal symptoms $(r=0.402, p=$ $0.047)$ 
[Insert Figure 3 near here]

Blood glucose, plasma cortisol and I-FABP concentration

A significant trial*time interaction was observed between groups for blood glucose concentration $(p=0.015)$, whereby CHO-S presented higher blood glucose responses during GC2, compared with CHO-F and PLA (Table 4). An increase in blood glucose concentration was observed in GC1 and GC2 during steady state and post distance test in all groups (Table 4). However, only on CHO-S was a significantly higher blood glucose concentration observed post distance test in GC2 compared with GC1. Blood glucose availability did not differ between male and female participants.

[Insert Table 4 near here]

No trial*time interaction was observed for plasma cortisol concentration. However, a significant main effect of time $(p<0.001)$ was observed (Table 5), whereby plasma cortisol concentration increased in response to steady state running and the distance test in all groups. Post distance test plasma cortisol concentration did not differ between male and female participants.

Similarly, no trial*time interaction was observed for plasma I-FABP concentration. Despite an increase in plasma I-FABP concentration post distance test in GC1 and GC2 in all groups, no main effect of time was observed due to the large individual variation (Table 5). Significant negative correlations were observed between post distance test plasma I-FABP concentration with gut discomfort $(r=-0.571, p=0.004)$, total gastrointestinal symptoms $(r=-0.473, p=0.022)$, and upper-gastrointestinal symptoms $(r=-0.509, p=0.013)$. Post distance test plasma I-FABP concentration did not differ between male and female participants. 
[Insert Table 5 near here] 


\section{Discussion}

The study aimed to determine the impact of two weeks gut-training using a gut-challenge protocol during exercise on gastrointestinal status, blood glucose availability, total carbohydrate oxidation, and running performance. Findings show that all participants found difficulties in tolerating the gut-challenge feeding dose at some point along GC1 as evidenced by gastrointestinal symptoms, carbohydrate malabsorption, and (or) total carbohydrate oxidation rates at the point of stressed glycogen stores well below recommendations for carbohydrate intake during endurance exercise, especially in female participants. In accordance with our hypothesis, two weeks of guttraining on both $\mathrm{CHO}-\mathrm{S}$ and $\mathrm{CHO}-\mathrm{F}$ improved running performance, likely due to improved gastrointestinal symptoms. Improved carbohydrate malabsorption and enhanced blood glucose availability on CHO-S may have also contributed to the improved running performance. Contrary to our hypothesis, two weeks of gut-training did not alter total carbohydrate oxidation rates during steady state exercise. A positive correlation was observed between breath $\mathrm{H}_{2}$ and gastrointestinal symptoms. Interestingly, there was an inverse relationship observed between plasma I-FABP concentration and gastrointestinal symptoms.

Gastrointestinal symptoms are common during endurance exercise, especially running (Costa et al. 2016; Pfeiffer et al. 2012). The cause/s of gastrointestinal symptoms appear to originate from exercise-induced gastrointestinal syndrome, in which splanchnic hypoperfusion and reduced enteric nervous system activity are likely to be key aetiological features (ter Steege and Kolkman 2012; van Wijck et al. 2012). It is, therefore, plausible that attempting to consume food above individual tolerance levels during this period of compromised gastrointestinal status may exacerbate symptoms. Considering that in the same laboratory conditions, running exercise for $2 \mathrm{~h}$ at $60 \%$ $\mathrm{VO}_{2 \max }$ in $20^{\circ} \mathrm{C}$ ambient conditions with the provisions of water only results in zero to minimal reports of gut discomfort and gastrointestinal symptoms amongst endurance athletes (Snipe et al. 2016a), the current study objectively confirms that consuming multi-transportable carbohydrates at $90 \mathrm{~g} \cdot \mathrm{h}^{-1}(10 \% \mathrm{w} / \mathrm{v})$ during running leads to severe gut discomfort and symptoms, which was more 
pronounced in female participants. The reported symptoms during the current study are considerably higher than previous observations where 8 participants performed $2 \mathrm{~h}$ cycling exercise at $63 \% \mathrm{VO}_{2 \max }$ whilst consuming $1.2 \mathrm{~g} \cdot \mathrm{min}^{-1}$ glucose $\left(72 \mathrm{~g} \cdot \mathrm{h}^{-1}\right)$ and $0.6 \mathrm{~g} \cdot \mathrm{min}^{-1}$ fructose $\left(36 \mathrm{~g} \cdot \mathrm{h}^{-1}\right)$ (Jentjens et al. 2004). It was also noted that gastrointestinal symptoms were substantially elevated in recovery within the current study (i.e., 56\% of participants in GC1), suggesting that exercise associated gastrointestinal symptoms may have implications for recovery nutrition (Beelan et al. 2010; van Wijck et al. 2013). This is especially relevant in events that are multi-day in nature and (or) during periods of intensified training load on consecutive days.

Upper-gastrointestinal symptoms (i.e., gastric bloating, belching, urge to regurgitate and regurgitation) were the main reported symptoms, likely attributed to the overwhelming gastric load above tolerance levels (Minami and McCallum 1984; Noakes et al. 1991). For example, it has previously been observed that acute episodes of substantially high intragastric pressure and intestinal load attenuates gastric emptying and orocaecal transit time through neural and hormonal feedback mechanisms along the gastrointestinal tract (Costill and Saltin 1974; (Miller et al. 1981; Minami and McCallum 1984). However, repeated ingestion of a test solution has been shown to maintain a consistent intragastric pressure resulting in an enhanced gastric emptying rate and improved stomach comfort (Lambert et al. 2008; Noakes et al. 1991). It is, therefore, not surprising that two weeks of gut-training (i.e., repetitive gut-challenge) on CHO-S and CHO-F resulted in marked reductions in gut discomfort and gastrointestinal symptoms in GC2. As the current study did not measure gastric emptying or orocaecal transit time, future gut-training studies could potentially use ${ }^{13} \mathrm{C}$-octanoic acid or ${ }^{13} \mathrm{C}$-acetate acid breath test, and $\mathrm{H}_{2}$-lactulose or $\mathrm{H}_{2}$ fructooligosaccharide challenge breath test techniques as non-invasive and practical methods to establish individual gastric emptying and orocaecal transit time, respectively (Bertram et al. 2014; D’Angelo et al. 2013; Scarpellini et al. 2013; Urita et al. 2002). Such methods would provide valuable insight into the underlying mechanism/s for the improved gastrointestinal symptoms observed with repetitive gut-challenge during running. 
A novel aspect of the current study was the use of $\mathrm{H}_{2}$ breath testing to determine exerciseinduced carbohydrate malabsorption in response to the multiple-transportable carbohydrate feeding during steady state exercise. Within the current participant cohort, $68 \%$ of participants presented breath $\mathrm{H}_{2}$ values indicative of carbohydrate malabsorption in $\mathrm{GC1}$ (Bates et al. 2010; Gasbarrini et al. 2009), likely due to overwhelmed intestinal carbohydrate transporters (i.e., GLUT5 and (or) SGLT1, with or without GLUT2 saturation), during a period when these transporters are compromised (Lang et al. 2006). These outcomes have performance and clinical implications considering an association between breath $\mathrm{H}_{2}$ concentration and symptoms was observed. Findings suggest that excessive carbohydrate intake during running above tolerance levels may overwhelm intestinal absorptive capacity leading to carbohydrate malabsorption and subsequent stimulation of the ileal brake mechanism (i.e., delayed gastric emptying and orocaecal transit) (Shin et al. 2013), which, in turn, may have contributed to the upper-gastrointestinal symptoms.

Two weeks of gut-training on CHO-S abolished the $\mathrm{H}_{2}$ peak in the recovery period. It is possible that the repetitive multiple-transportable carbohydrate challenge on CHO-S may have promoted upregulation of specific transport carriers (e.g., GLUT5 facilitated transporter for fructose and (or) SGLT1 active transporter for glucose at the enterocyte apical border, with or without upregulation of GLUT2 at the basolateral border) (Ferraris and Diamond 1997; Gray and Ingelfinger 1966; Nguyen et al. 2014; Shi et al. 1997). Indeed, increased circulatory glucose availability was seen on CHO-S in GC2 (7.2 (6.3-8.1) $\left.\mathrm{mMol} \cdot \mathrm{L}^{-1}\right)$ compared with GC1 (6.1 (5.5-6.7) $\mathrm{mMol} \cdot \mathrm{L}^{-1}$ ), and in adjunct with the reduction in breath $\mathrm{H}_{2}$, provides some evidence of upregulated carbohydrate intestinal absorption. Moreover, the greater reduction of breath $\mathrm{H}_{2}$ and increased glucose availability on CHO-S compared with $\mathrm{CHO}-\mathrm{F}$, in GC2, suggests the importance of specificity within gut-training protocols. For example, if the carbohydrate food portion was used in the gut-challenge protocols, instead of the carbohydrate gel-disc formulation, the study may have yielded different results. Interestingly, despite the increased circulatory glucose availability, total carbohydrate oxidation rates at the point of stressed glycogen stores (post distance test) did not 
differ. This contrasts with previous findings suggesting increased exogenous carbohydrate oxidation after twenty eight days on a high carbohydrate diet ( $v s$. low carbohydrate) was attributed to improved intestinal absorption (Cox et al. 2010). Future research should aim to determine the role of gut-training on intestinal carbohydrate transporter activity using non-metabolisable glucose analogue challenges, such as 3-O-methyl-glucose (SGLT1 activity) and D-xylose (GLUT5 activity) (Lang et al. 2006).

Epithelial injury is a key feature of exercise-induced gastrointestinal syndrome, which appears to originate from splanchnic hypoperfusion and subsequent gastrointestinal ischaemia (Evennett et al. 2009; Grootjans et al. 2016; ter Steege and Kolkman 2012; van Wijck et al. 2011; van Wijck et al. 2012). Despite evidence of increased epithelial injury after GC1 (144\%) and GC2 $(115 \%)$, this increase did not reach significance due to large individual variations (I-FABP range: GC1 82 to $4443 \mathrm{pg} \cdot \mathrm{ml}^{-1}$ and GC2 155 to $3172 \mathrm{pg} \cdot \mathrm{ml}^{-1}$ ). Also, two weeks of gut-training on CHO-S and CHO-F did not alter epithelial injury in response to prolonged running. An interesting finding however, was the inverse association between epithelial injury with gut discomfort and gastrointestinal symptoms. This suggests participants reporting the greatest frequency and severity of gastrointestinal symptoms had difficulties in tolerating the gut-challenge from a motility perspective (i.e., gastrointestinal trafficking), but the carbohydrate dose used potentially led to the maintenance of intestinal perfusion (van Wijck et al. 2011). Indeed, carbohydrate presence within the duodenum is a potent nutrient-mediator for hyperaemia in intestinal villi microvasculature (Matherson et al. 2000; Rehrer et al. 2005). A recent study showed that consumption of $15 \mathrm{~g}$ glucose before and every $20 \mathrm{~min}$ during running for $2 \mathrm{~h}$ at $60 \% \mathrm{VO}_{2 \max }$ in $35^{\circ} \mathrm{C}$ ambient temperature resulted in an abolition of exercise associated epithelial injury, compared with water alone (Snipe et al. 2016b). Conversely, considering participants that reported the lowest frequency and severity of gastrointestinal symptoms did not have difficulties in tolerating the gut-challenge, but presented substantially elevated plasma I-FABP concentration, the continuation of carbohydrate provisions during the distance test may have attenuated the intestinal epithelial injury without 
promoting further symptoms. These findings suggest the need to identify individual tolerance levels for carbohydrate provisions during exercise and provide tailored prescription.

From a practical perspective, the current findings provide evidence for the need to establish an assessment protocol for exercise-induced gastrointestinal syndrome to identify individual gastrointestinal issues, feeding tolerance, and to prescribe carbohydrate feeding rates during endurance running with the aim of finding a balance between managing symptoms and perturbations to intestinal integrity (i.e., epithelial injury). Additionally, measuring total carbohydrate oxidation using indirect calorimetry at the point of stressed muscle glycogen stores whilst consuming a multi-transportable carbohydrate formulation during exercise (e.g., $\geq 3 \mathrm{~h}$ strenuous exercise) would provide an estimated upper limit for carbohydrate intake tolerance. Such a method would be more practical and less invasive for practitioners and athletes, in comparison to research applied stable isotopic method, which have been documented to contain several limitations, including the need for exercise (e.g., depletion of ${ }^{13} \mathrm{C}$ glycogen stores) and prolonged dietary control (e.g., elimination and avoidance of ${ }^{13} \mathrm{C}$ rich foods) (Jentjens et al. 2004; Jentjens et al. 2005; Jentjens and Jeukendrup 2000). Outcomes of this assessment process would provide objective data to sports nutrition professionals and athletes, allowing informed decisions for individually tailored race nutrition advice. However, it is acknowledged that in a 'real-life' scenario, exercise associated gut perturbations and symptoms may be heightened considering the greater fluctuations in situational stress, compared to the laboratory setting. Thus, to confirm translational relevance, future studies should determine the impact of gut-training protocols in response to competitive events known to produce high rates of gastrointestinal symptoms (i.e., long course triathlon and ultra-marathon competitions).

\section{Conclusions}

Two weeks of gut-training using a carbohydrate gel-disc formulation improved gastrointestinal symptoms, reduced carbohydrate malabsorption, and enhanced blood glucose 
availability during endurance running, compared with a placebo. Using a carbohydrate food portion improves gastrointestinal symptoms only. The running performance improvements observed after gut-training are likely due to symptom improvement, but increased glucose availability may have also contributed on CHO-S. Gut-training did not alter fuel kinetics and epithelial injury, and thus are unlikely to have contributed to the performance improvements. The findings from the current study suggest that endurance runners may benefit from a structured gut-training protocol to meet individual needs and tolerance levels. It is, however, yet to be determined whether a greater nutrient load, for example inclusion of protein and fat, within the gut-training formulation and (or) food would result in greater gut-training effects. Considering the diversity of individualised responses observed for the markers of gastrointestinal status measured, the application of a gut-challenge protocol would be an essential part of the athlete assessment process, identifying individual gut issues and tolerance levels, and allowing for tailored training and race nutrition, with the aim of reducing the risk of exercise-induced gastrointestinal syndrome and subsequently enhancing performance. 


\section{Conflict of interest}

All authors report no conflicts of interest associated with this manuscript.

\section{Acknowledgements}

Firstly, the authors would like to thank all the participants that volunteered to take part in this study. The study was supported by Monash University, Department of Nutrition \& Dietetics. The authors also acknowledge The Runners Kitchen for providing the carbohydrate food used within the gut-training intervention (CHO-F). The authors' contributions are as follows: Ricardo Costa was the chief investigator of this research and responsible for the original research idea. Ricardo Costa and Peter Gibson contributed to the development of the experimental design. All authors contributed to the various aspects of sample and data collection and analysis. Ricardo Costa, Atlanta Miall and Vera Camões-Costa contributed to the analysis of the raw data. All authors contributed to the preparation and review of the manuscript. All authors read and approved the final manuscript. 


\section{References}

Bate, J.P., Irving, P.M., Barrett, J.S., and Gibson, P.R. 2010. Benefits of breath hydrogen testing after lactulose administration in analysing carbohydrate malabsorption. Eur. J. Gastroenterol. Hepatol. 22(3): 318-326. doi:10.1097/MEG.0b013e32832b20e8. PMID: 19636251.

Beelen, M., Burke, L.M., Gibala, M.J., and van Loon, L.J.C. 2010. Nutritional strategies to promote postexercise recovery. Int. J. Sport Nutri. Exerc. Metab. 20(6): 515-532. PMID: 21116024.

Bertram, F., Andresen, V., Layer, P., and Keller, J. 2014. Simultaneous non-invasive measurement of liquid gastric emptying and small bowel transit by combined $13 \mathrm{C}$-acetate and $\mathrm{H} 2$-lactulose breath test. J. Breath Res. 8(4): 046007. doi: 10.1088/1752-7155/8/4/046007. PMID: 25417651.

Burke, L.M., Hawley, J.A., Wong, S.H., and Jeukendrup, A.E. 2011. Carbohydrates for training and competition. J. Sports Sci. 29(Suppl 1): S17-S27. PMID: 21660838.

Costa, R.J.S., Crockford, M.J., Moore, J.P., and Walsh, N.P. 2014. Heat acclimation responses of an ultra-endurance running group preparing for hot desert based competition. Eur. J. Sport Sci. 14(S1): S131-S141. doi: 10.1080/17461391.2012.660506. PMID: 24444197.

Costa, R.J.S., Gill, S.K., Hankey, J., Wright, A., and Marczak, S. 2014. Perturbed energy balance and hydration status in ultra-endurance runners during a $24 \mathrm{~h}$ ultra-marathon. Br. J. Nutri., 112: 428-437. doi:10.1017/S0007114514000907. PMID:24818799.

Costa, R.J.S., Jones, G.E., Lamb, K.L., Coleman, R., and Williams, J.H. 2005. The effects of a high carbohydrate diet on cortisol and salivary immunoglobulin A (s-IgA) during a period of increase exercise workload amongst Olympic and Ironman triathletes. Int.J.Sports Med. 26(10): 880-885. doi: 10.1055/s-2005-837467. PMID: 16320174.

Costa, R.J.S., Oliver, S.J., Laing, S.J., Walters, R., Williams, S., Bilzon, J.L.J., and Walsh, N.P. 2009. Influence of timing of postexercise carbohydrate-protein ingestion on selected immune indices. Int. J. Sport Nutr. Exerc. Metab. 19(4): 366-284. PMID: 19827462. 
Costa, R.J.S., Swancott, A., Gill, S., Hankey, J., Scheer, V., Murray, A., and Thake, D. 2013. Compromised energy and nutritional intake of ultra-endurance runners during a multi-stage ultramarathon conducted in a hot ambient environment. Int. J. Sports Sci. 3(2): 51-61. doi:10.5923/j.sports.20130302.03.

Costa, R.J.S., Teixiera, A., Rama, L., Swancott, A., Hardy, L., Lee, B., Camões-Costa, V., Gill, S., Waterman, J., Barrett, E., Freeth, E., Hankey, J., Marczak, S., Valero, E., Scheer, V., Murray, A., and Thake, D. 2013. Water and sodium intake habits and status of ultra-endurance runners during a multi-stage ultra-marathon conducted in a hot ambient environment: An observational study. Nutri. J. 12(13): 1-16. doi: 10.1186/1475-2891-12-13. PMID: 23320854.

Costa, R.J.S., Snipe, R., Camões-Costa, V., Scheer, B.V., and Murray, A. 2016. The impact of gastrointestinal symptoms and dermatological injuries on nutritional intake and hydration status during ultramarathon events. Sports Medicine - Open. 2(16): 1-14. doi 10.1186/s40798-015-00419. PMID: 26767151.

Costill, D.L., and Saltin, B. 1974. Factors limiting gastric emptying during rest and exercise. J. Appl. Physiol. 37: 679-683. PMID: 4436193.

Cox, G.R., Clark, S.A., Cox, A.J., Halson, S.L., Hargreaves, M., Hawley, J.A., Jeacocke, N., Snow, R.J., Yeo, W.K., and Burke, L.M. 2010. Daily training with high carbohydrate availability increases exogenous carbohydrate oxidation during endurance cycling. Appl. Physiol. 109: 126-134. doi: 10.1152/japplphysiol.00950.2009. PMID: 20466803.

D'Angelo, G., Di Rienzo, T.A., Scaldaferri, F., Del Zompo, F., Pizzoferrato, M., Lopetuso, L.R., Laterza, L., Bruno, G., Petito, V., Campanale, M.C., Cesario, V., Franceschi, F., Cammarota, G., Gaetani, E., Gasbarrini, A., and Ojetti, V. 2013. Tricks for interpreting and making a good report on hydrogen and 13C breath test. Eur. Rev. Med. Pharmacol. Sci. 17(Suppl 2): 90-98. PMID: 24443074. 
Ebert, K., and Witt, H. 2016. Fructose malabsorption. Mol. Cell Pediatr. 3(1): 10. doi: 10.1186/s40348-016-0035-9. PMID: 26883354.

Evennett, N.J., Petrov, M.S., Mittal, A., and Windsor, J.A. 2009. Systematic review and pooled estimates for the diagnostic accuracy of serological markers for intestinal ischemia. World J. Surg. 33(7): 1374-1383. doi: 10.1007/s00268-009-0074-7. PMID: 19424744.

Ferraris, R.P., and Diamond, J. 1997. Regulation of intestinal sugar transport. Physiol. Rev. 77(1): 257-302. PMID: 9016304.

Fedewa, A., Rao, S.S.C. 2014. Dietary fructose intolerance, fructan intolerance and FODMAPs. Curr. Gastroenterol. Rep. 16(1): 370. doi: 10.1007/s11894-013-0370-0. PMID: 24357350.

Gasbarrini, A., Corazza, G.R., Gasbarrini, G., Montalto, M., Di Stefano, M., Basilisco, G., Parodi, A., Usai-Satta, P., Vernia, P., Anania, C., Astegiano, M., Barbara, G., Benini, L., Bonazzi, P., Capurso, G., Certo, M., Colecchia, A., Cuoco, L., Di Sario, A., Festi, D., Lauritano, C., Miceli, E., Nardone, G., Perri, F., Portincasa, P., Risicato, R., Sorge, M., and Tursi, A. 2009. Methodology and indications of H2-breath testing in gastrointestinal diseases: the Rome Consensus Conference._1st Rome H2-Breath Testing Consensus Conference Working Group. Aliment. Pharmacol. Ther. 29(Suppl 1): 1-49. doi: 10.1111/j.1365-2036.2009.03951. PMID: 19344474.

Gibson, P.R., Newnham, E., Barrett, J.S., Shepherd, S.J., Muir, J.G. 2007. Fructose Malabsorption and the bigger picture. Aliment. Pharmocol. Ther. 25(4): 349-363. PMID: 17217453.

Gill, S.K., Allerton, D.M., Ansley-Robson, P., Hemming, K., Cox, M., \& Costa, R.J.S. 2016. Does Acute High Dose Probiotic Supplementation Containing Lactobacillus casei Attenuate ExertionalHeat Stress Induced Endotoxaemia and Cytokinaemia? Int.J.Sports.Nutr.Exerc.Metab. 26(3): 268 275. doi.org/10.1123/ijsnem.2015-0186. PMID: 26568577.

Gill, S.K., Hankey, J., Wright, A., Marczak, S., Hemming, K., Allerton, D.M., Ansley-Robson, P., and Costa, R.J.S. 2015a. The Impact of a 24-hour Ultra-Marathon on Circulatory Endotoxin and Cytokine Profile. Int. J. Sports Med. 36: 688-695. doi: 10.1055/s-0034-1398535. PMID: 25941924. 
Gill, S.K., Teixeira, A., Rama, L., Rosado, F., Hankey, J., Scheer, V., Hemmings, K., AnsleyRobson, P., and Costa, R.J.S., 2015b. Circulatory endotoxin concentration and cytokine profile in response to exertional-heat stress during a multi-stage ultra-marathon competition. Exerc. Immunol. Rev. 21: 114-128. PMID: 25830597.

Gray GM, and Ingelfinger FJ. 1966. Intestinal absorption of sucrose in man: interrelation of hydrolysis and monosaccharide product absorption. J. Clin. Invest. 45: 388-398. PMID: 5904556.

Grootjans, J., Lenaerts, K., Buurman, W.A., Dejong, C.H., and Derikx, J.P. 2016. Life and death at the mucosal-luminal interface: New perspectives on human intestinal ischemia-reperfusion. World J. Gastroenterol. 22(9): 2760-2770. doi: 10.3748/wjg.v22.i9.2760. PMID: 26973414.

Hoffman, M.D., and Fogard, K. 2011. Factors related to successful completion of a 161-km ultramarathon. Int. J. Sports Physiol. Perform. 6(1): 25-37. PMID: 21487147.

Jentjens, R.L., and Jeukendrup, A.E. 2000. Oxidation of carbohydrate feedings during prolonged exercise: current thoughts, guidelines and directions for future research. Sports Med. 29(6): 407424. PMID: 10870867.

Jentjens, R.L., and Jeukendrup, A.E. 2005. High rates of exogenous carbohydrate oxidation from a mixture of glucose and fructose ingested during prolonged cycling exercise. Br. J. Nutr. 93(4): 485492. PMID: 15946410.

Jentjens, R.L., Moseley, L., Waring, R.H., Harding, L.K., and Jeukendrup, A.E. 2004. Oxidation of combined ingestion of glucose and fructose during exercise. J. Appl. Physiol. 96(4): 1277-1284. PMID: 14657042 .

Jentjens, R.L., Underwood, K., Achten, J., Currell, K., Mann, C.H., and Jeukendrup, A.E. 2006. Exogenous carbohydrate oxidation rates are elevated after combined ingestion of glucose and fructose during exercise in the heat. J. Appl. Physiol. 100(3): 807-816. PMID: 16282436. 
Jeukendrup, A.E. 2010. Carbohydrate and exercise performance: the role of multiple transportable carbohydrates. Curr. Opin. Clin. Nutr. Metab. Care. 13(4): 452-457.

doi: 10.1097/MCO.0b013e328339de9f. PMID: 20574242.

Jeukendrup, A.E, and McLaughlin, J. 2011. Carbohydrate ingestion during exercise: effects on performance, training adaptations and trainability of the gut. Nestle Nutr. Inst. Workshop Ser. 69: 112. doi: 10.1159/000329268. PMID: 22301833.

Jeukendrup, A.E., Vet-Joop, K., Sturk, A., Stegen, J.H., Senden, J., Saris, W.H., and Wagenmakers, A.J. 2000. Relationship between gastro-intestinal complaints and endotoxaemia, cytokine release and the acute-phase reaction during and after a long-distance triathlon in highly trained men. Clin. Sci. 98: 47-55. PMID: 10600658.

Lambert, G.P., Lang, J., Bull, A., Eckerson, J., Lanspa, S., and O’Brien, J. 2008. Fluid tolerance while running: effect of repeated trials. Int. J. Sports Med. 29(11): 878-882. doi: 10.1055/s-20081038620. PMID: 18512180.

Lambert, C.P., Ball, D., Leiper, J.B., and Maughan, R.J. 1999. The use of deuterium tracer technique to follow the fate of fluids ingested by human subjects: effects of drink volume and tracer concentration and content. Exp. Physiol. 84: 391-399. PMID: 10226179.

Lang, J.A., Gisolfi, C.V., and Lambert, G.P. 2006. Effect of exercise intensity on active and passive glucose absorption. Int. J. Sport Nutr. Exerc. Metab. 16(5): 485-493. PMID: 17240781.

Leiper, J.B. 2015. Fate of ingested fluids: factors affecting gastric emptying and intestinal absorption of beverages in humans. Nutr. Rev. 73(S2): 57-72. doi: 10.1093/nutrit/nuv032. PMID: 26290292.

Matherson, P.J., Wilson, M.A., and Garrison, R.N. 2000. Regulation of intestinal blood flow. J. Surg. Res. 93(1): 182-196. PMID: 10945962. 
Miller, L.J., Malagelada, J.R., Taylor, W.F., and Go, V.L. 1981. Intestinal control of human postprandial gastric function: the role of components of jejunoileal chyme in regulating gastric secretion and gastric emptying. Gastroenterol. 80: 763-769. PMID: 7202948.

Minami, H., and McCallum, R.W. 1984. The physiology and pathophysiology of gastric emptying in humans. Gastroenterol. 86: 1592-1610. PMID: 6370777.

Murray, K., Wilkinson-Smith, V., Hoad, C., Costigan, C., Cox, E., Lam, C., Marciani, L., Gowland, P., and Spiller, R.C. 2014. Differential effects of FODMAPs (fermentable oligo-, di-, monosaccharides and polyols) on small and large intestinal contents in healthy subjects shown by MRI. Am. J. Gastroenterol. 109: 110-119. doi: 10.1038/ajg.2013.386. PMID: 24247211.

Nguyen, N.Q., Debreceni, T.L., Bambrick, J.E., Chia, B., Deane, A.M., Wittert, G., Rayner, C.K., Horowitz, M., and Young, R.L. 2014. Upregulation of intestinal glucose transporters after Roux-enY gastric bypass to prevent carbohydrate malabsorption. Obesity. 22(10): 2164-2171. doi: 10.1002/oby.20829. PMID: 24990218.

Noakes, T.D., Rehrer, N.J., and Maughan, R.J. 1991. The importance of volume in regulating gastric emptying. Med. Sci. Sports Exerc. 23: 307-313. PMID: 1875801.

Oliver, S.J., Costa, R.J.S., Laing, S.J., Bilzon, J.L.J., and Walsh, N.P. 2009. One night of sleep deprivation decreases treadmill endurance performance. Eur. J. Appl. Physiol. 107(2): 155-161. doi: 10.1007/s00421-009-1103-9. PMID: 19543909.

Péronnet, F., and Massicotte, D. 1991. Table of nonprotein respiratory quotient: an update. Can. J. Sport Sci. 16(1): 23-29. PMID: 1645211.

Peters, H.P., Schep, G., Koster, D.J., Douwes, A.C., and de Vried, W.R. 1994. Hydrogen breath test as a simple noninvasive method for evaluation of carbohydrate malabsorption during exercise. Eur. J. Appl. Physiol. Occup. Physiol. 68(5): 435-440. PMID: 8076625. 
Pfeiffer, B., Stellingwerff, T., Hodgson, A.B., Randell, R., Pöttgen, K., Res, P., and Jeukendrup, A.E. 2012. Nutritional intake and gastrointestinal problems during competitive endurance events. Med. Sci. Sports Exerc. 44: 344-351. doi: 10.1249/MSS.0b013e31822dc809. PMID: 21775906.

Putkonen, L., Yao, C.K., and Gibson, P.R. 2013. Fructose malabsorption syndrome. Curr. Opin. Clin. Nutr. Metab. Care. 6(4): 473-477. doi: 10.1097/MCO.0b013e328361c556. PMID: 23739630.

Rehrer, N.J., Goes, E., DuGardeyn, C., Reynaert, H., and DeMeirleir, K. 2005. Effect of carbohydrate on portal vein blood flow during exercise. Int. J. Sports Med. 26: 171-176. PMID: 15776331.

Rowlands, D.S., Houltham, S., Musa-Veloso, K., Brown, F., Paulionis, L., Bailey, D. 2015. Fructose-glucose composite carbohydrates and endurance performance: Critical review and future perspectives. Sports Med. 45(11): 1561-1576. PMID: 26373645.

Scarpellini, E., Abenavoli, L., Balsano, C., Gabrielli, M., Luzza, F., and Tack, J. 2013. Breath tests for the assessment of the orocecal transit time. Eur. Rev. Med. Pharmacol. Sci. 17(Suppl 2): 39-44. PMID: 24443067.

Shi, X., Schedl, H.P., Summers, R.M., Lambert, G.P., Chang, R.T., Xia, T., and Gisolfi, C.V. 1997. Fructose transport mechanisms in humans. Gastroenterol. 113: 1171-1179. PMID: 9322512.

Shin, H.S., Ingram, J.R., McGill, A.T., and Poppitt, S.D. 2013. Lipids, CHOs, proteins: can all macronutrients put a 'brake' on eating? Physiol. Behav. 120: 114-123. doi: 10.1016/j.physbeh.2013.07.008. PMID: 23911804.

Smith, J., Pascoe, D.D., Passe, D.H., Ruby, B.C., Stewart, L.K., Barker, L.B., and Zachwieja, J.J. 2013. Curvilinear dose-response relationship of carbohydrate $\left(0-120 \mathrm{~g} \cdot \mathrm{h}^{-1}\right)$ and performance. Med. Sci. Sports Exerc. 45(2): 336-341. doi: 10.1249/MSS.0b013e31827205d1. PMID: 22968309. 
Snipe, R., Kitic, C., Gibson, P., and Costa, R.J.S. 2016a. Heat stress during prolonged running results in exacerbated intestinal epithelial injury and gastrointestinal symptoms. Exercise and Sports Science Australia Annual Conference- Abstract.

Snipe, R., Kitic, C., Gibson, P., and Costa, R.J.S. 2016b. Carbohydrate and protein intake during exertional-heat stress ameliorates intestinal epithelial damage. Nutri. Diet. 73(Suppl. 1): 19.

Stellingwerff, T., and Cox, G.R. 2014. Systematic review: Carbohydrate supplementation on exercise performance or capacity of varying durations. Appl. Physiol. Nutr. Metab. 39: 1-14.doi: 10.1139/apnm-2014-0027. PMID: 24951297.

Stuempfle, K.J., and Hoffman, M.D. 2015. Gastrointestinal distress is common during a $161-\mathrm{km}$ ultramarathon. J. Sports Sci. 33(17): 1814-1821. doi: 10.1080/02640414.2015.1012104. PMID: 25716739.

ter Steege, R.W., and Kolkman, J.J. 2012. The pathophysiology and management of gastrointestinal symptoms during physical exercise, and the role of splanchnic blood flow. Aliment. Pharmacol. Ther. 35: 516-528. doi: 10.1111/j.1365-2036.2011.04980.x. PMID: 22229513.

ter Steege, R.W.F., Van Der Palen, J., Kolkman, J.J. 2008. Prevalence of gastrointestinal complaints in runners competing in a long-distance run: An internet-based observational study in 1281 subjects. Scand. J. Gastroenterol. 43: 1477-1482. doi: 10.1080/00365520802321170. PMID: 18777440.

Truswell, A.S., Seach, J.M., Thorburn, A.W. 1988. Incomplete absorption of pure fructose in healthy subjects and the facilitating effect of glucose. Am. J. Clin. Nutr. 48(6):1424-30. PMID: 3202090.

Urita, Y., Hike, K., Torii, N., Kikuchi, Y., Sasajima, M., and Miki, K. 2002. Efficacy of lactulose plus $13 \mathrm{C}$-acetate breath test in the diagnosis of gastrointestinal motility disorders. J. Gastroenterol. 37(6): 442-428. PMID: 12108678. 
van Wijck, K., Lenaerts, K., Grootjans, J., Wijnands, K.A., Poeze, M., van Loon, L.J., Dejong, C.H., and Buurman, W.A. 2012. Physiology and pathophysiology of splanchnic hypoperfusion and intestinal injury during exercise: strategies for evaluation and preventions. Am. J. Physiol. 303: G155-G168. doi: 10.1152/ajpgi.00066.2012. PMID: 22517770.

van Wijck, K., Lenaerts, K., van Loon, L.J., Peters, W.H., Buurman, W.A., and Dejong, C.H. 2011. Exercise-induced splanchnic hypoperfusion results in gut dysfunction in healthy men. PLoS One. 6(7): e22366. doi: 10.1371/journal.pone.0022366. PMID: 21811592.

van Wijck, K., Pennings, B., van Bijnen, A.A., Senden, W.A., Buurman, W.A., Dejong, C.H., van Loon, L.J., and Lenaerts, K. 2013. Dietary protein digestion and absorption are impaired during acute postexercise recovery in young men. Am. J. Phyiol. Regul. Integr. Comp. Physiol. 304(5): R356-R361. doi: 10.1152/ajpregu.00294.2012. PMID: 23283940. 
Table 1. Total carbohydrate and fat oxidation rates during $2 \mathrm{~h}$ steady state running exercise at $60 \% \mathrm{VO}_{2 \max }$ while consuming $30 \mathrm{gCHO} \cdot 20 \mathrm{~min}{ }^{-1} 2: 1$ glucose-fructose ratio and $1 \mathrm{~h}$ running distance test before (gut-challenge 1: GC1) and after (gut-challenge 2: GC2) two weeks of gut-training with carbohydrate supplement gel-disc formulation (CHO-S), carbohydrate food (CHO-F), and placebo (PLA).

\begin{tabular}{|c|c|c|c|c|c|c|c|}
\hline & \multicolumn{6}{|c|}{ Steady state } & \multirow{2}{*}{$\begin{array}{l}\text { Post distance test } \\
180 \mathrm{~min}\end{array}$} \\
\hline & $20 \mathrm{~min}$ & $40 \mathrm{~min}$ & $60 \mathrm{~min}$ & $80 \mathrm{~min}$ & $100 \mathrm{~min}$ & $120 \mathrm{~min}$ & \\
\hline \multicolumn{8}{|c|}{ Carbohydrate oxidation $\left(\mathrm{g} \cdot \mathrm{min}^{-1}\right)$} \\
\hline $\begin{array}{l}\text { CHO-S } \\
\text { GC1 } \\
\text { CG2 }\end{array}$ & $\begin{array}{l}1.5(1.1-1.9) \\
1.6(1.2-2.0)\end{array}$ & $\begin{array}{l}1.5(1.2-1.9) \\
1.5(1.0-2.0)\end{array}$ & $\begin{array}{l}1.6(1.2-1.9) \\
1.5(1.2-1.9)\end{array}$ & $\begin{array}{l}1.7(1.3-2.0) \\
1.6(1.2-1.9)\end{array}$ & $\begin{array}{l}1.6(1.3-2.0) \\
1.6(1.2-1.9)\end{array}$ & $\begin{array}{l}1.6(1.2-1.9) \\
1.5(1.2-1.8)\end{array}$ & $\begin{array}{c}\dagger \dagger \\
0.9(0.7-1.2) \\
0.8(0.6-1.1)\end{array}$ \\
\hline $\begin{array}{l}\text { CHO-F } \\
\text { GC1 } \\
\text { CG2 }\end{array}$ & $\begin{array}{l}2.1(1.5-2.6) \\
2.0(1.7-2.2)\end{array}$ & $\begin{array}{l}2.2(1.6-2.7) \\
2.0(1.7-2.2)\end{array}$ & $\begin{array}{l}2.1(1.5-2.7) \\
2.0(1.6-2.3)\end{array}$ & $\begin{array}{l}2.1(1.6-2.7) \\
2.0(1.8-2.3)\end{array}$ & $\begin{array}{l}2.0(1.5-2.6) \\
1.9(1.8-2.1)\end{array}$ & $\begin{array}{l}2.1(1.6-2.5) \\
2.0(1.8-2.1)\end{array}$ & $\begin{array}{l}1.3(0.8-1.9) \\
1.2(1.1-1.4)\end{array}$ \\
\hline $\begin{array}{l}\text { PLA } \\
\text { GC1 } \\
\text { CG2 }\end{array}$ & $\begin{array}{l}1.8(1.5-2.1) \\
1.8(1.4-2.4)\end{array}$ & $\begin{array}{l}1.5(1.1-2.0) \\
1.8(1.2-2.3)\end{array}$ & $\begin{array}{l}1.8(1.3-2.3) \\
1.8(1.4-2.3)\end{array}$ & $\begin{array}{l}1.7(1.3-2.2) \\
1.9(1.5-2.3)\end{array}$ & $\begin{array}{c}1.6(1.3-2.0) \\
1.8(1.4-2.1)\end{array}$ & $\begin{array}{l}1.7(1.4-2.0) \\
1.8(1.4-2.1)\end{array}$ & $\begin{array}{l}1.1(0.7-1.5) \\
1.2(0.8-1.6)\end{array}$ \\
\hline \multicolumn{8}{|c|}{ Fat oxidation $\left(\mathrm{g} \cdot \mathrm{min}^{-1}\right)$} \\
\hline $\begin{array}{l}\text { CHO-S } \\
\text { GC1 } \\
\text { CG2 }\end{array}$ & $\begin{array}{l}0.7(0.4-0.9) \\
0.5(0.4-0.6)\end{array}$ & $\begin{array}{l}0.6(0.5-0.7) \\
0.5(0.5-0.6)\end{array}$ & $\begin{array}{l}0.6(0.5-0.7) \\
0.6(0.4-0.7)\end{array}$ & $\begin{array}{l}0.6(0.4-0.7) \\
0.5(0.4-0.6)\end{array}$ & $\begin{array}{l}0.6(0.5-0.7) \\
0.5(0.4-0.6)\end{array}$ & $\begin{array}{l}0.6(0.5-0.7) \\
0.5(0.4-0.7)\end{array}$ & $\begin{array}{c}\dagger_{\dagger}^{\dagger} \\
0.8(0.7-1.0) \\
0.8(0.6-1.0)\end{array}$ \\
\hline $\begin{array}{l}\text { CHO-F } \\
\text { GC1 } \\
\text { CG2 }\end{array}$ & $\begin{array}{l}0.5(0.3-0.6) \\
0.5(0.3-0.8)\end{array}$ & $\begin{array}{l}0.5(0.3-0.7) \\
0.6(0.3-0.8)\end{array}$ & $\begin{array}{l}0.5(0.3-0.7) \\
0.6(0.3-0.8)\end{array}$ & $\begin{array}{l}0.5(0.3-0.7) \\
0.5(0.3-0.8)\end{array}$ & $\begin{array}{l}0.6(0.3-0.8) \\
0.6(0.4-0.9)\end{array}$ & $\begin{array}{l}0.6(0.4-0.8) \\
0.6(0.3-0.8)\end{array}$ & $\begin{array}{l}0.8(0.6-1.1) \\
0.9(0.7-1.1)\end{array}$ \\
\hline $\begin{array}{l}\text { PLA } \\
\text { GC1 } \\
\text { CG2 }\end{array}$ & $\begin{array}{l}0.6(0.4-0.8) \\
0.6(0.4-0.7)\end{array}$ & $\begin{array}{l}0.6(0.4-0.7) \\
0.6(0.5-0.8)\end{array}$ & $\begin{array}{l}0.6(0.5-0.8) \\
0.6(0.4-0.7)\end{array}$ & $\begin{array}{l}0.6(0.4-0.7) \\
0.6(0.5-0.8)\end{array}$ & $\begin{array}{l}0.6(0.4-0.8) \\
0.6(0.5-0.8)\end{array}$ & $\begin{array}{l}0.6(0.4-0.9) \\
0.6(0.5-0.8)\end{array}$ & $\begin{array}{l}0.9(0.6-1.2) \\
0.9(0.7-1.1)\end{array}$ \\
\hline
\end{tabular}




\section{Applied Physiology, Nutrition, and Metabolism}

Mean and 95\% confidence interval $(n=25)$. Main effect of time $\dagger \dagger p<0.01$ vs. steady state. 
Table 2. Frequency of participants reporting occurrence of moderate (M) and severe (S) total, upper-, and lower-gastrointestinal symptoms in response to $2 \mathrm{~h}$ steady state running exercise at $60 \% \mathrm{VO}_{2 \max }$ while consuming $30 \mathrm{gCHO} \cdot 20 \mathrm{~min}^{-1} 2: 1$ glucose-fructose ratio and $1 \mathrm{~h}$ running distance test (gut-challenge 1: GC1).

\begin{tabular}{|c|c|c|c|c|c|c|c|c|c|}
\hline & & \multicolumn{4}{|c|}{ Steady state } & \multicolumn{2}{|r|}{$\begin{array}{c}\text { Post distance } \\
\text { test }\end{array}$} & \multicolumn{2}{|c|}{ Recovery } \\
\hline & & $0 \mathrm{~min}$ & $30 \mathrm{~min}$ & $60 \mathrm{~min}$ & $90 \mathrm{~min}$ & $120 \mathrm{~min}$ & $180 \mathrm{~min}$ & $1 \mathrm{~h}$ & $2 \mathrm{~h}$ \\
\hline \multirow[t]{2}{*}{ Total gastrointestinal symptoms (\%) } & $\mathrm{M}$ & 16 & 76 & 88 & 100 & 92 & 92 & 56 & 56 \\
\hline & $\mathrm{S}$ & 0 & 20 & 24 & 44 & 44 & 52 & 20 & 20 \\
\hline \multirow[t]{2}{*}{ Upper gastrointestinal symptoms (\%) } & M & 8 & 76 & 72 & 96 & 80 & 72 & 40 & 32 \\
\hline & $\mathrm{S}$ & 0 & 20 & 20 & 36 & 40 & 40 & 12 & 8 \\
\hline \multirow[t]{2}{*}{ Lower gastrointestinal symptoms (\%) } & M & 8 & 24 & 20 & 24 & 40 & 44 & 24 & 20 \\
\hline & $\mathrm{S}$ & 0 & 0 & 0 & 0 & 8 & 20 & 12 & 12 \\
\hline \multirow[t]{2}{*}{ Nausea } & $\mathrm{M}$ & 4 & 12 & 20 & 32 & 44 & 32 & 24 & 24 \\
\hline & $\mathrm{S}$ & 0 & 0 & 0 & 12 & 8 & 16 & 12 & 8 \\
\hline
\end{tabular}

Percentage of total participant numbers $(n=25)$. Upper-gastrointestinal symptoms (gastro-oesophageal and gastro-duodenal originated): projectile vomiting, regurgitation, urge to regurgitate, gastric bloating, belching, stomach pain, and heartburn/gastric acidosis), and lower-gastrointestinal symptoms (intestinal originated): flatulence including lower-abdominal bloating, urge to defecate, abdominal pain, abnormal defecation including loose watery stools, diarrhoea and blood in stools. 
Table 3. Gut discomfort, total, upper-, and lower-gastrointestinal symptoms in response to $2 \mathrm{~h}$ steady state running exercise at $60 \% \mathrm{VO}_{2 \text { max }}$ while consuming $30 \mathrm{gCHO} \cdot 20 \mathrm{~min}^{-1}$ 2:1 glucose-fructose ratio and $1 \mathrm{~h}$ running distance test before (gut-challenge 1: GC1) and after (gut-challenge 2: GC2) two weeks of gut-training with carbohydrate supplement gel-disc formulation (CHO-S), carbohydrate food (CHO-F), and placebo (PLA).

\begin{tabular}{|c|c|c|c|c|c|c|c|c|}
\hline \multicolumn{3}{|c|}{ CHO-S } & \multicolumn{3}{|c|}{ CHO-F } & \multicolumn{3}{|c|}{ PLA } \\
\hline $\mathrm{GC} 1^{\ddagger}$ & $\mathrm{GC} 2$ & $p$ value & $\mathrm{GC} 1^{*}$ & $\mathrm{GC} 2^{*}$ & $p$ value & $\mathrm{GC} 1^{*}$ & $\mathrm{GC} 2$ & $p$ value \\
\hline \multicolumn{9}{|l|}{ Gut discomfort } \\
\hline $49(31-74)$ & $27(13-49)$ & .008 & $52(33-76)$ & $25(6-35)^{b}$ & .028 & $43(13-69)$ & $26(7-57)$ & .101 \\
\hline \multicolumn{9}{|c|}{ Total gastrointestinal symptoms } \\
\hline $131(59-311)$ & $57(13-131)^{b}$ & .009 & $79(65-168)$ & $46(7-74)^{b}$ & .046 & $51(17-168)$ & $38(6-127)$ & .237 \\
\hline \multicolumn{9}{|c|}{ Upper-gastrointestinal symptoms } \\
\hline $49(21-207)$ & $26(6-71)^{b}$ & .015 & $71(19-116)$ & $30(0-58)$ & .028 & $43(10-123)$ & $32(4-75)$ & .310 \\
\hline \multicolumn{9}{|c|}{ Lower-gastrointestinal symptoms } \\
\hline $37(19-70)$ & $21(10-45)$ & .008 & $21(0-38)$ & $5(0-15)^{b}$ & .173 & $10(4-14)$ & $4(0-41)$ & .889 \\
\hline \multicolumn{9}{|l|}{ Nausea } \\
\hline $6(0-15)$ & $0(0-7)^{b}$ & .050 & $4(0-12)$ & $1(0-8)$ & .343 & $1(0-16)$ & $2(0-11)$ & .674 \\
\hline
\end{tabular}

Median and interquartile range $(n=25) .{ }^{b}$ degree of reduction $p<0.05 v s$. PLA. ${ }^{\sharp}$ Values indicative of summative accumulation of rating scale point score of measured time periods. Upper-gastrointestinal symptoms (gastro-oesophageal and gastro-duodenal originated): projectile vomiting, regurgitation, urge to regurgitate, gastric bloating, belching, stomach pain, and heartburn/gastric acidosis), and lower-gastrointestinal symptoms 
(intestinal originated): flatulence including lower-abdominal bloating, urge to defecate, abdominal pain, abnormal defecation including loose watery stools, diarrhoea and blood in stools. 
Table 4. Blood glucose concentration during $2 \mathrm{~h}$ steady state running exercise at $60 \% \mathrm{VO}_{2 \max }$ while consuming $30 \mathrm{gCHO} \cdot 20 \mathrm{~min}^{-1} 2: 1 \mathrm{glucose}$-fructose ratio and $1 \mathrm{~h}$ running distance test before (gut-challenge 1: GC1) and after (gut-challenge 2: GC2) two weeks of gut-training with carbohydrate supplement gel-disc formulation (CHO-S), carbohydrate food (CHO-F), and placebo (PLA).

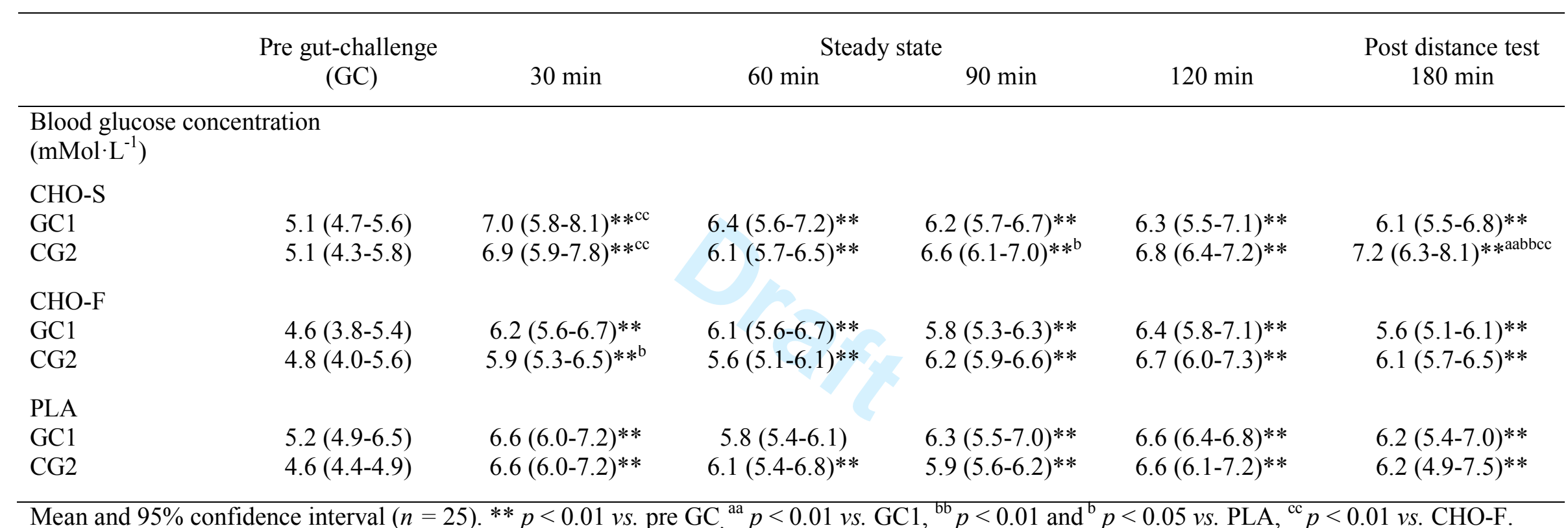


Table 5. Plasma I-FABP and cortisol concentration in response to $2 \mathrm{~h}$ steady state running exercise at $60 \% \mathrm{VO}_{2 \max }$ while consuming $30 \mathrm{gCHO} \cdot 20 \mathrm{~min}^{-1} 2: 1$ glucose-fructose ratio and $1 \mathrm{~h}$ running distance test before (gut-challenge 1: GC1) and after (gut-challenge 2: GC2) two weeks of guttraining with carbohydrate supplement gel-disc formulation (CHO-S), carbohydrate food (CHO-F), and placebo (PLA).

\begin{tabular}{|c|c|c|c|}
\hline & $\begin{array}{c}\text { Pre gut-challenge } \\
(\mathrm{GC})\end{array}$ & Post distance test & $\begin{array}{c}2 \mathrm{~h} \text { post distance } \\
\text { test }\end{array}$ \\
\hline $\begin{array}{l}\text { Plasma I- } \\
\left(\mathrm{pg} \cdot \mathrm{ml}^{-1}\right)\end{array}$ & P concentration & & \\
\hline $\begin{array}{l}\mathrm{CHO}-\mathrm{S} \\
\mathrm{GC} 1 \\
\mathrm{CG} 2\end{array}$ & $\begin{array}{l}434(103-764) \\
536(326-744)\end{array}$ & $\begin{array}{l}981(256-1705) \\
848(366-1330)\end{array}$ & $\begin{array}{l}642(351-933) \\
527(216-838)\end{array}$ \\
\hline $\begin{array}{l}\mathrm{CHO}-\mathrm{F} \\
\mathrm{GC} 1 \\
\mathrm{CG} 2\end{array}$ & $\begin{array}{l}450(149-753) \\
467(183-710)\end{array}$ & $\begin{array}{l}1236(451-2923) \\
1462(106-2818)\end{array}$ & $\begin{array}{l}662(165-1160) \\
835(425-1245)\end{array}$ \\
\hline $\begin{array}{l}\text { PLA } \\
\text { GC1 } \\
\text { CG2 }\end{array}$ & $\begin{array}{c}517(74-960) \\
467(148-846)\end{array}$ & $\begin{array}{l}1243(254-2203) \\
1040(126-1954)\end{array}$ & $\begin{array}{l}865(203-1466) \\
796(237-1355)\end{array}$ \\
\hline $\begin{array}{l}\text { Plasma c } \\
\left(\mathrm{ng} \cdot \mathrm{ml}^{-1}\right)\end{array}$ & 1 concentration & 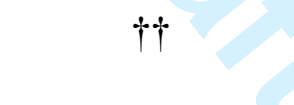 & \\
\hline $\begin{array}{l}\text { CHO-S } \\
\text { GC1 } \\
\text { CG2 }\end{array}$ & $\begin{array}{l}146(124-168) \\
142(102-181)\end{array}$ & $\begin{array}{l}211(146-275) \\
216(159-273)\end{array}$ & --- \\
\hline $\begin{array}{l}\mathrm{CHO}-\mathrm{F} \\
\mathrm{GC} 1 \\
\mathrm{CG} 2\end{array}$ & $\begin{array}{c}94(52-136) \\
127(90-163)\end{array}$ & $\begin{array}{l}256(127-386) \\
253(138-367)\end{array}$ & $\begin{array}{l}--- \\
---\end{array}$ \\
\hline $\begin{array}{l}\text { PLA } \\
\text { GC1 } \\
\text { CG2 }\end{array}$ & $\begin{array}{l}118(76-160) \\
122(87-156)\end{array}$ & $\begin{array}{l}267(227-306) \\
224(170-278)\end{array}$ & $\begin{array}{l}--- \\
---\end{array}$ \\
\hline
\end{tabular}

Mean and 95\% confidence interval $(n=25)$. †† Main effect of time $p<0.01 v s$. pre GC. 


\section{Figure legends}

Figure 1. Schematic description of the experimental design. CHO-S: carbohydrate (CHO) supplement gel-disc formulation (males $n=5$ and females $n=5$ ), CHO-F: carbohydrate food (males $n=5$ and females $n=2$ ), PLA: placebo (males $n=5$ and females $n=3$ ), GC1: gut-challenge 1, and GC2: gut-challenge 2.

Figure 2. Difference in running distance covered in response to a $1 \mathrm{~h}$ running distance test after two weeks of gut-training with carbohydrate supplement gel-disc formulation (CHO-S), carbohydrate food (CHO-F), and placebo (PLA). GC1: gut-challenge 1, and GC2: gut-challenge 2. Mean $\pm \mathrm{SD}$ ( $n$ $=25):{ }^{\text {aa }} p<0.01$ vs. GC1, ${ }^{\mathrm{bb}} p<0.01$ and ${ }^{\mathrm{b}} p<0.05$ vs. PLA.

Figure 3. Breath $\mathrm{H}_{2}$ in response to $2 \mathrm{~h}$ steady state running exercise at $60 \% \mathrm{VO}_{2 \max }$ while consuming $30 \mathrm{gCHO} \cdot 20 \mathrm{~min}^{-1} 2: 1$ glucose-fructose ratio and $1 \mathrm{~h}$ running distance test before (gutchallenge $1: \mathrm{GC1} ; \mathbf{\square})$ and after (gut-challenge 2 : GC2; $\square$ ) two weeks of gut-training with (A) carbohydrate supplement gel-disc formulation, (B) carbohydrate food, and (C) placebo. Mean \pm SD $(n=25):{ }^{*} p<0.01$ and $* p<0.05$ vs. 0 min, ${ }^{\text {aa }} p<0.01$ and ${ }^{\mathrm{a}} p<0.05 v s . \mathrm{GC} 1,{ }^{\mathrm{bb}} p<0.01$ and ${ }^{\mathrm{b}} p$ $<0.05$ vs. PLA, ${ }^{\mathrm{cc}} p<0.01$ and ${ }^{\mathrm{c}} p<0.05$ vs. CHO-F.

DT: Distance test. 


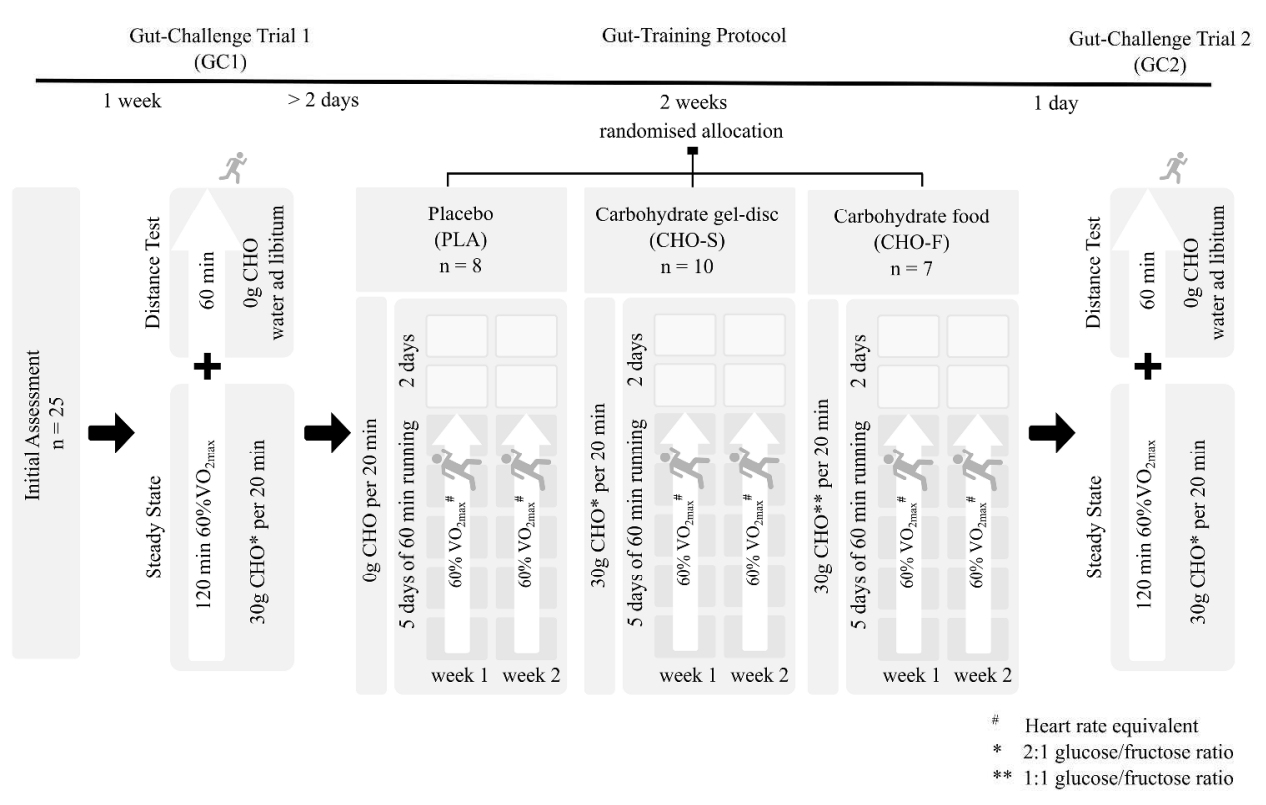

Figure 1. Schematic description of the experimental design. CHO-S: carbohydrate (CHO) supplement geldisc formulation (males $\mathrm{n}=5$ and females $\mathrm{n}=5$ ), CHO-F: carbohydrate food (males $\mathrm{n}=5$ and females $\mathrm{n}=$

2), PLA: placebo (males $n=5$ and females $n=3$ ), GC1: gut-challenge 1, and GC2: gut-challenge 2 . [Insert Figure 1 near here] $511 \times 333 \mathrm{~mm}(300 \times 300 \mathrm{DPI})$ 


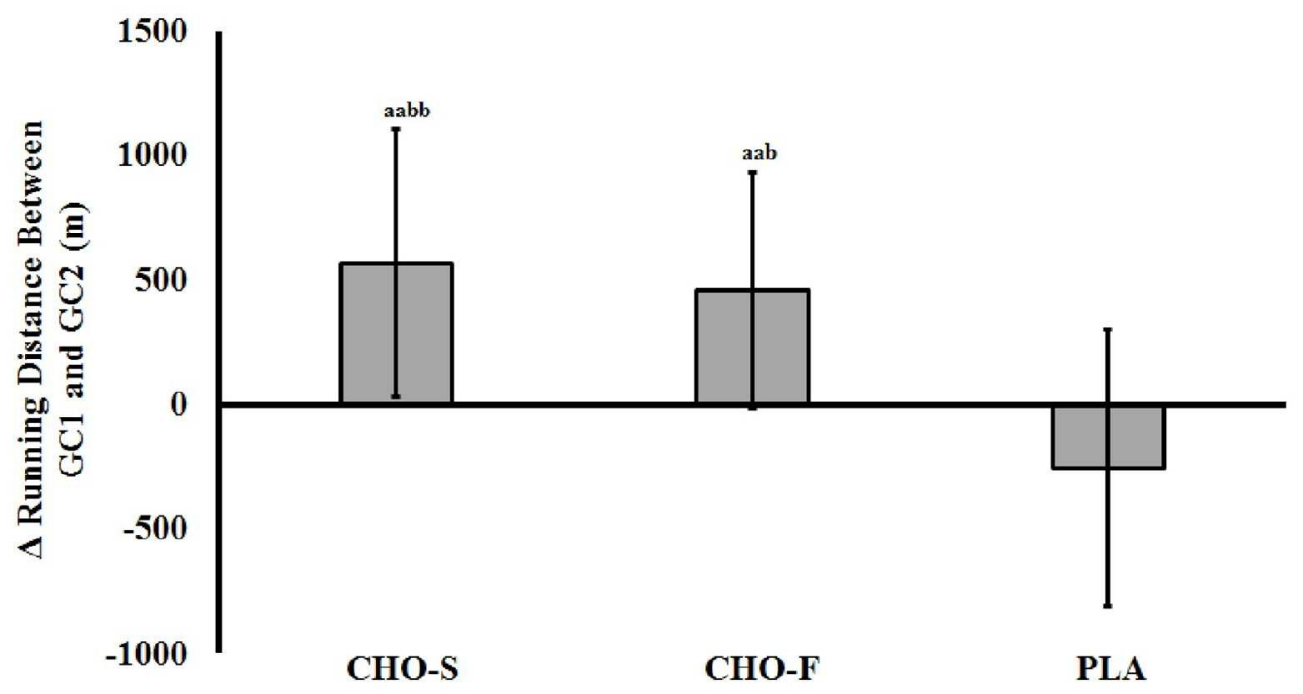

Figure 2. Difference in running distance covered in response to a $1 \mathrm{~h}$ running distance test after two weeks of gut-training with carbohydrate supplement gel-disc formulation ( $\mathrm{CHO}-\mathrm{S})$, carbohydrate food (CHO-F), and placebo (PLA). GC1: gut-challenge 1, and GC2: gut-challenge 2. Mean $\pm \mathrm{SD}(\mathrm{n}=25)$ : aa $\mathrm{p}<0.01$ vs. GC1, bb $p<0.01$ and $b p<0.05$ vs. PLA.

[Insert Figure 2 near here]

$135 \times 75 \mathrm{~mm}(300 \times 300 \mathrm{DPI})$ 

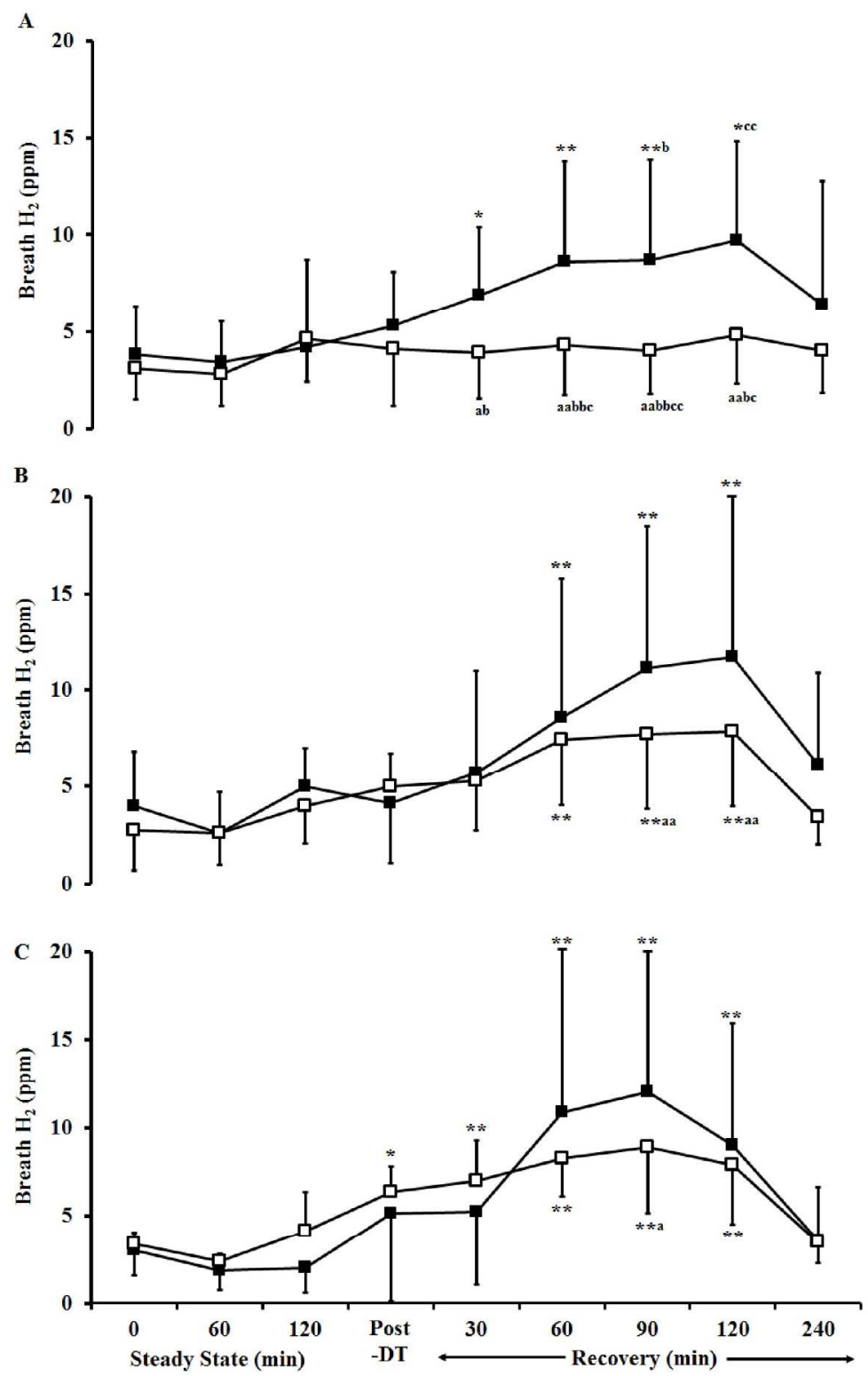

Figure 3. Breath $\mathrm{H} 2$ in response to $2 \mathrm{~h}$ steady state running exercise at $60 \%$ VO2max while consuming 30 gCHO 20 min-1 2:1 glucose-fructose ratio and $1 \mathrm{~h}$ running distance test before (gut-challenge $1: \mathrm{GC} 1 ; \mathbf{-})$ and after (gut-challenge 2: GC2; 口) two weeks of gut-training with (A) carbohydrate supplement gel-disc formulation, (B) carbohydrate food, and (C) placebo. Mean $\pm \operatorname{SD}(n=25): * * p<0.01$ and $* p<0.05$ vs. 0 $\min$, aa $p<0.01$ and $a p<0.05$ vs. GC1, bb $p<0.01$ and $b p<0.05$ vs. PLA, cc $p<0.01$ and $c p<0.05$ vs. CHO-F.

DT: Distance test.

[Insert Figure 3 near here] $137 \times 217 \mathrm{~mm}(300 \times 300 \mathrm{DPI})$ 